\title{
Hospice Use Among Nursing Home and Non-Nursing Home Patients
}

\author{
Kathleen T. Unroe, MD, MHA ${ }^{1,2,3,5}$, Greg A. Sachs, MD ${ }^{1,2,3,5}$, M. E. Dennis, BA ${ }^{2}$, Susan E. Hickman, PhD ${ }^{4,5}$, \\ Timothy E. Stump, $M A^{3}$, Wanzhu Tu, $P h D^{1,2}$, and Christopher M. Callahan, $M D^{1,2,3}$
}

Indiana University Center for Aging Research, Indianapolis, IN, USA; ${ }^{2}$ Regenstrief Institute, Inc., Indianapolis, IN, USA; ${ }^{3}$ nndiana University School of Medicine, Indianapolis, IN, USA; ${ }^{4}$ Indiana University School of Nursing, Indianapolis, IN, USA; ${ }^{5}$ RESPECT Signature Center at IUPUI, Indianapolis, IN, USA.

\begin{abstract}
BACKGROUND: For nursing home patients, hospice use and associated costs have grown dramatically. A better understanding of hospice in all care settings, especially how patients move across settings, is needed to inform debates about appropriateness of use and potential policy reform. OBJECTIVE: Our aim was to describe characteristics and utilization of hospice among nursing home and nonnursing home patients.
\end{abstract}

DESIGN AND PARTICIPANTS: Medicare, Medicaid and Minimum Data Set data, 1999-2008, were merged for 3,771 hospice patients aged 65 years and above from a safety net health system. Patients were classified into four groups who received hospice: 1) only in nursing homes; 2) outside of nursing homes; 3) crossover patients utilizing hospice in both settings; and 4) "near-transition" patients who received hospice within 30 days of a nursing home stay. MAIN MEASURES: Differences in demographics, hospice diagnoses and length of stay, utilization and costs are presented with descriptive statistics.

KEY RESULTS: Nursing home hospice patients were older, and more likely to be women and to have dementia $(p<0.0001)$. Nearly one-third $(32.3 \%)$ of crossover patients had hospice stays $>6$ months, compared with the other groups (16\% of nursing home hospice only, $10.7 \%$ of nonnursing home hospice and $7.6 \%$ of those with near transitions) ( $\mathrm{p}<0.0001)$. Overall, $27.7 \%$ of patients had a hospice stay $<1$ week, but there were marked differences between groups- $48 \%$ of near-transition patients vs. $7.4 \%$ of crossover patients had these short hospice stays $(\mathrm{p}<0.0001)$. Crossover and near-transition hospice patients had higher costs to Medicare compared to other groups ( $\mathrm{p}<0.05)$.

CONCLUSIONS: Dichotomizing hospice users only into nursing home vs. non-nursing home patients is difficult, due to transitions across settings. Hospice patients with transitions accrue higher costs. The impact of changes to the hospice benefit on patients who live or move through nursing homes near the end of life should be carefully considered.

KEY WORDS: hospice; nursing home; costs.

J Gen Intern Med 30(2):193-8

DOI: $10.1007 / \mathrm{s} 11606-014-3080-\mathrm{x}$

(c) Society of General Internal Medicine 2014

Received April 1, 2014

Revised July 29, 2014

Accepted October 20, 2014

Published online November 6, 2014

\section{BACKGROUND}

Rising costs, long lengths of hospice stay, and concerns over possible duplication of services have led to increased scrutiny by policymakers of hospice patients living in nursing homes. ${ }^{1-4}$ Medicare spending on hospice care for nursing home patients grew $70 \%$ between 2005 and 2009. ${ }^{5}$ Compared to patients in others settings, nursing home patients tend to have longer hospice stays, ${ }^{6}$ which are more costly to Medicare, as hospice is reimbursed on a per diem basis. Longer stays have been associated with a lower intensity of services provided by hospice, raising the issue of the degree of value added to the usual care of nursing home patients. ${ }^{7,8}$

A 2011 Office of the Inspector General (OIG) report proposed several recommendations to the Centers for Medicare and Medicaid Services (CMS), including more intensive monitoring for hospices that enroll large numbers of nursing home patients and a reduction in hospice payments for patients who live in nursing homes. ${ }^{5}$ The CMS May 2013 Proposed Rule addressing hospice payment recommended a site of service payment adjustment-reducing hospice per diem payments for patients in nursing homes - based largely on the concern that hospice aide care duplicated usual nursing home care, and that nursing home beneficiaries may be receiving less complex care. The CMS Final Rule, released in August 2013, did not adopt these changes, though concerns about the current model for hospice care for nursing home patients were emphasized. ${ }^{9}$

Despite debate about the current structure of the benefit, hospice care in the nursing home setting has been associated with significant benefits, including improved pain and symptom management, ${ }^{10,11}$ reduced hospitalizations, ${ }^{12}$ and improved family satisfaction. ${ }^{13,14}$ Thus, changes to the hospice benefit could decrease access to end-of-life care services for this vulnerable population. A better understanding of both the characteristics and global health care utilization of hospice patients in nursing homes compared to those in other settings is needed to inform proposed changes to the hospice benefit. The picture is complicated by patients who transition across settings near the end of life. In a previous paper, we mapped patterns and reported frequencies of patients who moved in and out of nursing homes while on hospice. The most common pattern was enrolling in hospice care and subsequently transitioning into a nursing home for the remainder of the 
hospice episode (54\%); next was enrolling while a nursing home patient and then transitioning out of the facility ( $33 \%$ ); and least common was transitioning into a nursing home and then back out again while remaining on hospice $(13 \%) .{ }^{15} \mathrm{~A}$ more detailed characterization of patients who cross over settings while on hospice, or transition into or out of nursing home around hospice enrollment, could highlight the implications of proposed policy changes.

Building on prior analyses, this paper explores the clinical characteristics of both nursing home and non-nursing home hospice users, as well as utilization patterns for patients who move across settings while on hospice. Using a unique database of patients from a safety net health system, we specifically sought to: 1) describe differences in the demographic and clinical characteristics of hospice patients who live in different settings and move between settings, including crossing over settings while on hospice and enrolling in hospice near to a nursing home transition; 2) describe patterns, including length of stay, in hospice and other healthcare utilization; and 3) report differences in costs.

\section{METHODS}

Overview. This study was approved by the Indiana University Purdue University- Indianapolis Institutional Review Board and the Centers for Medicare and Medicaid Services Privacy Board. The data set was created by merging electronic medical record data from a single safety net health care system with Medicare claims, Indiana Medicaid claims, and Minimum Data Set (MDS) reports. ${ }^{16,17}$ MDS assessments are required on admission and repeated at specified intervals for all nursing home residents who reside at facilities that accept Medicare and Medicaid. MDS data allows us to identify nursing home utilization regardless of payer. Patients included in this study had at least one clinical encounter within Wishard Health Services, one of the five largest safety net health systems in the country. Although subjects were identified initially through contact with Wishard, the Medicare, Indiana Medicaid, and MDS data captured utilization for services inside and outside of this system. Data were collected over an 11 year period (1999-2009).

Sample. We identified four patient cohorts who received hospice care: 1) only in nursing homes; 2) only in nonnursing home settings; 3 ) a crossover group of patients that utilized hospice in both settings; and 4) a "near-transition" group who received hospice within 30 days of a transition in or out of a nursing home. The near-transition group did not spend time in a nursing home while on hospice, but as they did utilize nursing homes so close to hospice enrollment, we were interested in examining their utilization and costs compared to the other groups.
Episodes of hospice and nursing home use were identified using claims and MDS assessments. To be included in the nursing home hospice cohort, patients had to have a hospice admission date in the range of 1 January 1999 to 31December 2008. Hospice length of stay was defined as continuous hospice enrollment. For those patients with more than one episode of nursing home care, we used the last nursing home stay and the last hospice stay associated with that nursing home stay. We eliminated duplicate records of nursing home and hospice care patients, which consisted of 34 nursing home and 79 hospice records, leaving us with one record per subject. The crossover group includes patients admitted or discharged from a nursing home during a continuous hospice stay if the hospice care did not end upon admission or discharge from a nursing home. Hospice days are categorized and paid based on acuity of the patient - Routine Home Care (Medicare revenue code 0651) is the most common code used. For the purpose of this analysis, we collapsed Medicare revenue codes 0655 and 0656 (Inpatient Respite Care and General Inpatient Care) into one category-Inpatient.

Data Collection. Variables that were extracted included demographic characteristics, comorbidities and health care utilization. Medicare and Medicaid International Classification of Disease (ICD 9) codes present in claims files at the time of hospice enrollment were used to define comorbidity with indicators of coronary artery disease, congestive heart failure, hypertension, arthritis, diabetes, chronic obstructive pulmonary disease and stroke. Primary hospice diagnosis categories included dementia, failure to thrive, heart disease, lung disease, cancer or "other."

Analysis. After identifying the four cohorts, we examined patient characteristics and utilization patterns using descriptive statistics. Chi-square and t-tests were used to compare demographic and clinical characteristics. Utilization outcomes (e.g., days on hospice) were analyzed using models for count data. A generalized linear model using a negative binomial distribution was used for group comparisons of utilization outcomes. Costs, including means, standard deviations and medians, were examined as 1) total costs to Medicare, and 2) total costs per day. These descriptive statistics were done for both Medicare and Medicaid costs for dual eligible patients in the sample. All cost data was stratified into mutually exclusive hospice length of stay categories: 1-7 days, 8-30 days, 31-90 days, 91-180 days, and $>180$ days. Cost comparisons were performed using a Wald test to account for zero costs and skewness in cost distributions.

\section{RESULTS}

Of the 33,378 older adults in the total sample, there were 13,746 deaths ( $41 \%$ ) over 11 years of follow-up; the analysis 
sample consisted of 3,771 (27.4 \%) decedents who received hospice care, of whom $96.5 \%$ died during the study period (Table 1). Among all hospice patients, 1142 (30.3\%) were enrolled in hospice only while in nursing homes, 1,963 $(52.1 \%)$ were in non-nursing home hospice, $310(8.2 \%)$ were "crossover" patients (i.e., moved into or out of the nursing home while in hospice), and 356 (9.4\%) were "near-transition" patients, spending time in a nursing home within 30 days of hospice enrollment. As shown in Table 1, nursing home hospice patients were older, more likely to be women and dual eligibles. Dementia as a comorbidity was less prevalent among the non-nursing home patients. Cancer was still the leading primary hospice diagnosis for all categories. The nursinghome-only hospice patients, however, had nearly equal rates of dementia as a primary diagnosis - about one-quarter for both cancer and dementia. Also, the diagnosis of failure to thrive was much more common for the nursing-home-only group.

As shown in Table 2, the number of days on hospice was dramatically higher for the crossover group, with a mean of 198.2 days and median of 91.5 days. Nearly one-third $(32.3 \%)$ of the crossover group had stays of greater than 6 months on hospice, compared with $16 \%$ of nursing-homeonly patients, $10.7 \%$ of non-nursing home patients and $7.6 \%$ of near-transition patients. Hospice episodes of a week or less were common, but markedly so for the near-transition group (48\%). About $70 \%$ of hospice patients overall received all of their hospice care through the Routine Home Care benefit, while $28 \%$ received the more expensive Inpatient Care hospice. The near-transition group was much more likely than the other two groups to receive hospice care billed exclusively as Inpatient Care. While about three-fourths of the entire sample were hospitalized in the year prior to hospice enrollment (76\%), hospitalization was less common after hospice enrollment $(10 \%)$.

There were significant differences in total Medicare costs among the groups. Looking across multiple time periods, total Medicare costs were lower for non-nursing home hospice patients for stays greater than 30 days $(\mathrm{p}<0.05)$ (Fig. 1).

We also examined costs per day to Medicare (i.e., costs from hospice election until death) for mutually exclusive time periods. The crossover and the near-transition groups consistently incurred higher Medicare costs per day; greater cost differences were seen for shorter stays.

Examination of combined costs to Medicare and Medicaid per day for dual eligibles reveals a somewhat different pattern. Crossover and near-transition patients still incur higher costs per day for shorter hospice stays (e.g., less than a week); mean costs for crossover patients were $\$ 498$, near-transition were $\$ 488$, non-nursing home were $\$ 324$ and nursing-home-only were $\$ 251 \quad(\mathrm{p}<0.05)$. Nursing-home-only patients, however, had highest combined mean costs per day for hospice stays greater than a month. For the 91-180 day time period, nursing-homeonly patients' mean costs were $\$ 285$, crossover patients' costs were $\$ 221$, near-transition patients' costs were $\$ 192$, and non-nursing home patients' mean costs were $\$ 147$ per day $(\mathrm{p}<0.05)$.

Table 1. Baseline Characteristics of the Study Population-Nursing Home Hospice Versus Home Hospice Patients

\begin{tabular}{|c|c|c|c|c|c|c|}
\hline Characteristic & $\begin{array}{l}\text { All hospice } \\
\text { patients } \\
(\mathrm{n}=\mathbf{3 7 7 1})\end{array}$ & $\begin{array}{l}\text { Nursing home } \\
\text { hospice only } \\
(\mathrm{n}=1142)\end{array}$ & $\begin{array}{l}\text { Hospice in multiple } \\
\text { settings (crossover) } \\
(n=310)\end{array}$ & $\begin{array}{l}\text { Near-transition } \\
\text { group }(n=356)\end{array}$ & $\begin{array}{l}\text { Non-nursing } \\
\text { home hospice } \\
(\mathrm{n}=1963)\end{array}$ & p value \\
\hline $\begin{array}{l}\text { Age at hospice enrollment, } \\
\text { mean (SD) }\end{array}$ & $79.1(8.2)$ & $81.8(8.1)$ & $78.9(8.2)$ & $79.7(8.2)$ & $77.4(7.9)$ & $<0.0001$ \\
\hline Male, No. $(\%)$ & $1564(41.5)$ & $410(35.9)$ & $134(43.2)$ & $140(39.3)$ & $880(44.8)$ & $<0.0001$ \\
\hline White race, No. (\%) & $2344(62.2)$ & $684(59.9)$ & $186(60.0)$ & $203(57.0)$ & $1271(64.8)$ & 0.0054 \\
\hline $\begin{array}{l}\text { Dual eligible Medicaid/ } \\
\text { Medicare, No. (\%) }\end{array}$ & $1979(52.5)$ & $904(79.2)$ & $188(60.7)$ & $181(50.8)$ & $706(36.0)$ & $<0.0001$ \\
\hline Dementia & $2135(56.6)$ & $939(82.2)$ & $155(50.0)$ & $229(64.3)$ & $812(41.4)$ & $<0.0001$ \\
\hline CAD & $2225(59.0)$ & $779(68.2)$ & $171(55.2)$ & $236(66.3)$ & $1039(52.9)$ & $<0.0001$ \\
\hline $\mathrm{CHF}$ & $2078(55.1)$ & $729(63.8)$ & $162(52.3)$ & $228(64.0)$ & $959(48.9)$ & $<0.0001$ \\
\hline HTN & $3316(87.9)$ & $1059(92.7)$ & $250(80.7)$ & $326(91.6)$ & $1681(85.6)$ & $<0.0001$ \\
\hline Arthritis & $2306(61.2)$ & $810(70.9)$ & $175(56.5)$ & $243(68.3)$ & $1078(54.9)$ & $<0.0001$ \\
\hline Diabetes & $1850(49.1)$ & $673(58.9)$ & $154(49.7)$ & $188(52.8)$ & $835(42.5)$ & $<0.0001$ \\
\hline COPD & $2228(59.1)$ & $674(59.0)$ & $192(61.9)$ & $230(64.6)$ & $1132(57.7)$ & 0.0668 \\
\hline Stroke & $872(23.1)$ & 315 (27.6) & $63(20.3)$ & $102(28.7)$ & $392(20.0)$ & $<0.0001$ \\
\hline$>=3$ comorbidities & 3486 (92.4) & $1115(97.6)$ & $274(88.4)$ & $336(94.4)$ & $1761(89.7)$ & $<0.0001$ \\
\hline \multicolumn{7}{|l|}{$\begin{array}{l}\text { Primary hospice diagnosis, } \\
\text { No. }(\%)\end{array}$} \\
\hline Cancer & $1478(39.2)$ & $278(24.3)$ & $145(46.8)$ & $99(27.8)$ & $956(48.7)$ & $<0.0001$ \\
\hline Dementia & $485(12.9)$ & $275(24.1)$ & $41(13.2)$ & $33(9.3)$ & $136(6.9)$ & $<0.0001$ \\
\hline Failure to thrive & $204(5.4)$ & $130(11.4)$ & $11(3.6)$ & $7(2.0)$ & $56(2.9)$ & $<0.0001$ \\
\hline Heart disease & $388(10.3)$ & $103(9.0)$ & $27(8.7)$ & $47(13.2)$ & $211(10.8)$ & 0.0875 \\
\hline Lung disease & $360(9.6)$ & $80(7.0)$ & 39 (12.6) & $57(16.0)$ & $184(9.4)$ & $<0.0001$ \\
\hline Other & $856(22.7)$ & $276(24.2)$ & $47(15.2)$ & $113(31.7)$ & $420(21.4)$ & $<0.0001$ \\
\hline Died, No. (\%) & $3639(96.5)$ & $1112(97.4)$ & $295(95.2)$ & $347(97.5)$ & $1885(96.0)$ & 0.0889 \\
\hline
\end{tabular}

Notes: group comparison on age was performed using a general linear regression model; all other comparisons used chi-square test 
Table 2. Health Care Utilization by Hospice Patients

\begin{tabular}{|c|c|c|c|c|c|c|}
\hline Characteristic & $\begin{array}{l}\text { All hospice } \\
\text { patients } \\
(\mathrm{n}=3771)\end{array}$ & $\begin{array}{l}\text { Nursing home } \\
\text { hospice only } \\
(\mathrm{n}=1142)\end{array}$ & $\begin{array}{l}\text { Hospice in multiple } \\
\text { settings (crossover) } \\
(\mathrm{n}=\mathbf{3 1 0})\end{array}$ & $\begin{array}{l}\text { Near-transition } \\
\text { group }(n=356)\end{array}$ & $\begin{array}{l}\text { Non-nursing } \\
\text { home hospice } \\
(n=1963)\end{array}$ & $p$ value \\
\hline Days on hospice, mean (SD) & $84.5(162.8)$ & $90.5(154.9)$ & $198.2(299.8)$ & $46.2(115.1)$ & $70.0(133.8)$ & $<0.0001$ \\
\hline Days on hospice, median & & & 91.5 & & & \\
\hline$\leq 7$ days on hospice, No. (\%) & $1043(27.7)$ & $313(27.4)$ & $23(7.4)$ & $171(48.0)$ & $536(27.3)$ & $<0.0001$ \\
\hline$>180$ days on hospice, No. (\%) & $520(13.8)$ & $183(16.0)$ & $100(32.3)$ & 27 (7.6) & $210(10.7)$ & $<0.0001$ \\
\hline $\begin{array}{l}\text { Any hospitalization in year } \\
\text { before hospice, No. }(\%)\end{array}$ & $2849(75.6)$ & $864(75.7)$ & $221(71.3)$ & $320(89.9)$ & $1444(73.6)$ & $<0.0001$ \\
\hline $\begin{array}{l}\text { Any hospitalization during or } \\
\text { after hospice ended, No. (\%) }\end{array}$ & $375(9.9)$ & $114(10.0)$ & $66(21.3)$ & $35(9.8)$ & $160(8.2)$ & $<0.0001$ \\
\hline $\begin{array}{l}\text { Total inpatient days among } \\
\text { those hospitalized, mean (SD); } \\
\text { median }\end{array}$ & $12.4(17.1) ; 7$ & $14.8(19.3) ; 8$ & $11.4(20.7) ; 6$ & 11.5 (10.9); 7 & $11.3(14.6) ; 6$ & 0.1063 \\
\hline $\begin{array}{l}\text { Emergency department visit } \\
\text { during or after hospice ended, } \\
\text { No. }(\%)\end{array}$ & $417(11.1)$ & $116(10.2)$ & $71(22.9)$ & $30(8.4)$ & $200(10.2)$ & $<0.0001$ \\
\hline $\begin{array}{l}\text { Disenrollment prior to death, } \\
\text { No. }(\%)\end{array}$ & $522(13.8)$ & 159 (13.9) & $56(18.1)$ & $58(16.3)$ & $249(12.7)$ & 0.0345 \\
\hline $\begin{array}{l}\% \text { of disenrolled dead at } \\
6 \text { months }\end{array}$ & $295(56.5)$ & $80(50.3)$ & $32(57.1)$ & $43(74.1)$ & $140(56.2)$ & 0.0200 \\
\hline $\begin{array}{l}\% \text { of disenrolled dead at } \\
12 \text { months }\end{array}$ & $339(64.9)$ & $98(61.6)$ & $38(67.9)$ & $44(75.9)$ & $159(63.9)$ & 0.2468 \\
\hline \multicolumn{7}{|l|}{ Hospice site, No. (\%) } \\
\hline Home only & $2666(70.7)$ & $977(85.6)$ & $172(55.5)$ & $157(44.1)$ & $1360(69.3)$ & $<0.0001$ \\
\hline Home and inpatient & $411(10.9)$ & $68(6.0)$ & $114(36.8)$ & $22(6.2)$ & $207(10.6)$ & $<0.0001$ \\
\hline Inpatient only & $649(17.2)$ & $84(7.4)$ & $23(7.4)$ & $172(48.3)$ & $370(18.9)$ & $<0.0001$ \\
\hline Site not specified & $45(1.2)$ & $13(1.1)$ & $1(0.3)$ & $5(1.4)$ & $26(1.3)$ & 0.4855 \\
\hline
\end{tabular}

Notes: group comparisons for days on hospice, costs per day and total inpatient days were performed using a generalized linear regression model with negative binomial distribution to account for the skewness in these distributions; all other comparisons used chi-square test. RHC=routine hospice care

\section{DISCUSSION}

Nursing home patients need consistent access to high quality end-of-life and palliative care services. There has been a dramatic growth in the use of the Medicare hospice benefit for this population over the past decade in response to this need. Unfortunately, a variety of factors have caused policymakers to question the role of the hospice benefit in this setting. Several findings from this study merit further discussion in the context of proposals to reform hospice payments. First, we found important differences in clinical characteristics of the populations receiving hospice in the nursing facility setting compared to other settings. Second, we found important differences in patterns of care for "crossover" and "neartransition" groups of patients who move across settings near the end of life. Third, there is a large group of nursing home hospice patients with very short lengths of hospice stay. We will discuss these issues below.

These analyses strengthen findings from previous research suggesting that patients who receive hospice while living in a nursing home differ in important ways from hospice patients in other settings. ${ }^{18,19}$ Most notably, these patients are older and have higher rates of dementia. In addition to clinical differences, the package of services needed to support a patient at the end of life might be expected to vary based on whether the patient lives in a facility with 24-hour, trained staff or at home. Because hospices create individualized care plans based on patient needs, a onesize-fits-all approach for reimbursement may not be an appropriate financial model. Using 1998-1999 data from a large hospice provider, researchers reported that nursing home residents did not receive a lower volume of services, but did receive a different mix of services. ${ }^{20}$ More research is needed to obtain a clearer, updated picture of the appropriateness of services provided by hospices matched to patient needs. Patient-level data are needed to inform discussions of hospice reimbursement policy.

While discussions about hospice use in nursing homes often dichotomize the population into two groups - nursing home and non-nursing home - in our study, we also examined hospice patients who moved across settings of care. Patients in this "crossover" group may enroll in hospice in the community and transition into a nursing home, or enroll in hospice while in a nursing home and transition to the community. Over half of the crossover patients enrolled in hospice while living at home and then transferred into a nursing home, presumably as their care needs became greater than they or their caregivers could manage at home. About one-third crossed over from the nursing home to home while on hospice, transitioning back to a community setting for the very end of life. "Near-transition" patients in our study did not receive hospice while in a nursing home, but spent time in a nursing home within 30 days of hospice enrollment. These high cost near-transition patients were more likely to receive intensive inpatient hospice services and have short lengths of hospice stay, suggesting a higher acuity. Some of these patients were nursing home residents who were discharged from the facility just prior to death, spending the last days of life in an inpatient hospice facility. They may have benefitted from earlier hospice enrollment while in the facility, or perhaps more highly trained 


\section{Total Medicare Costs after Hospice Enrollment}

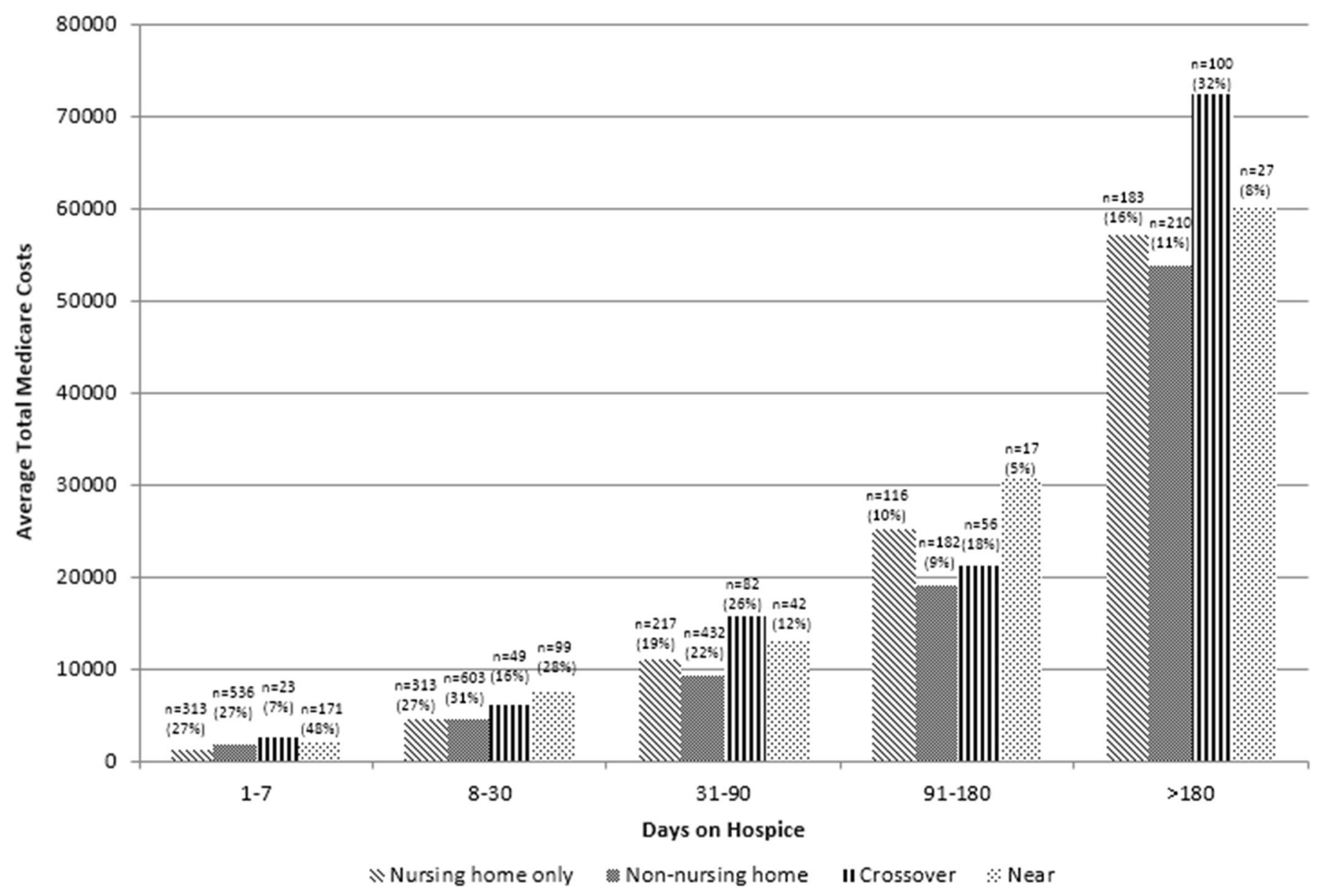

Figure 1. Notes: Comparisons significant at $\mathbf{p}<0.05$ for each time period.

nursing home staff could have delivered symptom management support in place. Crossover and near-transition hospice patients had higher costs to Medicare compared to other groups. These costs were statistically different from the other groups, although absolute differences were not large.

Another finding that merits discussion has to do with variations in hospice length of stay. As in other studies, nursing home hospice patients have longer lengths of stay. ${ }^{5}$ This subgroup of patients with very long lengths of stay, however, must be viewed in the context of the striking finding of a large percentage of "late referrals" who receive hospice care for a week or less. Late referrals were prevalent both in the home and nursing home settings. Very short stays on hospice may make it difficult for hospice care to impact quality of life of the patient and reduce the opportunity for cost savings by Medicare by avoided hospitalizations. ${ }^{21,22}$ Policies that discourage longer lengths of hospice stay may inadvertently increase the percentage of very late referrals, which could reduce the cost benefit ratio of hospice care. If changing rules and incentives lead to reduced access to hospice care for nursing home patients, there is little existing infrastructure to provide palliative or end-of-life care to this frail population. ${ }^{23-26}$
There are some limitations to this study. Our cohort of patients was drawn from one safety net health system, which serves a disproportionately poor, non-white patient population, many of whom are dually eligible for Medicare and Medicaid. In addition, our study encompassed a 10-year period, a span during which Medicare hospice utilization increased significantly throughout the U.S., including within nursing homes. According to an analysis of hospice use by nursing home patients, $33 \%$ of Indiana nursing home decedents received hospice care in 2006 - the same as the national average. ${ }^{6}$ Although we report costs to Medicare and Medicaid for hospice patients, we cannot address the cost-effectiveness of hospice care as we did not examine health care utilization by non-hospice patients. Also, we are unable to address appropriateness or quality of hospice provided in nursing homes compared to other settings.

Although these analyses cannot answer the important question of what is the "right" amount of hospice use by the "right" nursing home patient, they do provide a description of many key characteristics of hospice patients in nursing homes compared with other settings. We describe patients starting with enrollment on hospice and examine them in a prospective manner, reflecting the way that patients move through the health care system, as opposed to the common approach of starting with decedents and 
looking backwards. We also highlight the large numbers of patients who transition across settings and who could be impacted by changes in the role of hospice in nursing homes.

The National Hospice and Palliative Care Organization lodged several objections to the 2013 CMS proposed site-ofservice payment adjustment targeting nursing home patients, emphasizing that this recommendation "lacks supporting data and is based on incomplete information." They further stated that such a broad change is not appropriate to address narrow concerns, such as some hospices targeting specific categories of profitable enrollees, and could have significant impact on access to hospice care. ${ }^{27}$ As the debate over hospice use in nursing homes continues, many also advocate for an increase in palliative care services outside of the hospice benefit to meet the needs of patients with serious, chronic diseases such as dementia, but an uncertain illness trajectory. ${ }^{23,28,29}$ The findings of this study provide data that will hopefully inform this debate.

\section{CONCLUSION}

Hospice patients who live in nursing homes differ from those in other settings by several key clinical characteristics. Most notably, they have higher rates of dementia. As has been consistently noted, nursing home patients tend to have longer lengths of hospice stay, but a significant number have stays less than 7 days, which may limit the utility of the hospice benefit. Many hospice patients move in and out of nursing homes near the end of life, and may experience disruptions in care if the hospice benefit is changed based on setting alone. More research is needed to understand the added value of hospice to nursing home care, from a patient and policy perspective, and to define the optimal approach to delivering excellent palliative and end-of-life care to this vulnerable population.

Acknowledgements: The work is supported by NPCRC grant \#4183655, NIA grant RO1 AG031222 and K24 AG024078. All authors were involved in the analysis, writing and editing of this manuscript. There are no other contributors to acknowledge.

Conflict of Interest: The authors declare that they do not have a conflict of interest.

Corresponding Author: Kathleen T. Unroe, MD, MHA; Indiana University Center for Aging Research, 410 West 10th Street, Suite 2000, Indianapolis, IN 46202, USA (e-mail: kunroe@iu.edu).

\section{REFERENCES}

1. Medpac. Hospice services: Assessing payment adequacy and updating payments Medpac; 2012 [August 2012]; Available from: http:// medpac.gov/documents/reports/march-2012-report-to-the-congressmedicare-payment-policy.pdf?sfvrsn=0. Accessed September 8, 2014.

2. Medpac. Report to Congress: Medicare Payment Policy: Hospice Services. 2012; Chapter 11:[Available from: http://medpac.gov/documents / reports/march-2012-report-to-the-congress-medicare-paymentpolicy.pdf?sfvrsn=0. Accessed September 8, 2014.

3. Office of Inspector General. Medicare hospice care for beneficiaries in nursing facilities: compliance with Medicare coverage requirements. Washington, DC: U.S. Department of Health and Human Services; Sep 2009.

4. Abt Associates. Medicare Hospice Payment Reform: A Review of the Literature. Cambridge, MA: Abt Associates; 2012; Available from: http://www.cms.gov/ Medicare/Medicare-Fee-for-Service-Payment/Hospice/Downloads/HospicePayment-Reform-Literature-Review.pdf. Accessed September 8, 2014.

5. Office of Inspector General. Medicare Hospices that Focus on Nursing Facility Residents. Washington, DC: US Department of Health and Human Services; 2011.

6. Miller SC, Lima J, Gozalo PL, et al. The growth of hospice care in U.S. nursing homes. J Am Geriatr Soc. 2010;58(8):1481-8.

7. Nicosia N, Reardon $\mathbf{E}$, Lorenz $\mathbf{K}$, et al. The Medicare hospice payment system: a consideration of potential refinements. Health Care Financ Rev. 2009;30(4):47-59.

8. Huskamp HA, Newhouse JP, Norcini JC, et al. Variation in patients' hospice costs. Inquiry. 2008;45(2):232-44.

9. Federal Registry. Medicare Program; FY 2014 Hospice Wage Index and Payment Rate Update; Hospice Quality Reporting Requirements; and Updates on Payment Reform. Washington, DC: Daily Journal of the United States Government; May 10, 2013; Available from: https:// www.federalregister.gov/articles/2013/05/10/2013-10389/medicareprogram-fy-2014-hospice-wage-index-and-payment-rate-update-hospicequality-reporting\#h-30. Accessed September 8, 2014.

10. Miller SC, Mor V, Teno J. Hospice enrollment and pain assessment and management in nursing homes. J Pain Symptom Manag. 2003;26(3):791-9.

11. Stevenson DG, Bramson JS. Hospice care in the nursing home setting: a review of the literature. J Pain Symptom Manag. 2009;38(3):440-51.

12. Gozalo PL, Miller SC. Hospice enrollment and evaluation of its causal effect on hospitalization of dying nursing home patients. Health Serv Res. 2007;42(2):587-610.

13. Baer WM, Hanson LC. Families' perception of the added value of hospice in the nursing home. J Am Geriatr Soc. 2000;48(8):879-82.

14. Teno JM, Gozalo PL, Lee IC, et al. Does hospice improve quality of care for persons dying from dementia? J Am Geriatr Soc. 2011;59(8):1531-6.

15. Unroe KT, Sachs GA, Hickman SE, et al. Hospice Use Among Nursing Home Patients. J Am Med Dir Assoc. 2013;14(4):254-9.

16. Callahan CM, Arling G, Tu W, et al. Transitions in care for older adults with and without dementia. J Am Geriatr Soc. 2012;60(5):813-20.

17. Hendrie HC, Lindgren D, Hay DP, et al. Comorbidity Profile and Healthcare Utilization in Elderly Patients With Serious Mental Illnesses. Am J Geriatr Psychiatry. 2012.

18. Medicare Payment Advisory Commission. Report to the Congress: Medicare Payment Policy—Chapter 6: Reforming Medicare's hospice benefit. Washington, DC: Medpac.Gov; 2009; Available from: http://medpac.gov/documents/ reports/Mar09_Ch06.pdf?sfvrsn=0. Accessed September 9, 2012.

19. Stevenson DG, Huskamp HA, Grabowski DC, et al. Differences in hospice care between home and institutional settings. J Palliat Med. 2007;10(5):1040-7.

20. Miller SC. Hospice care in nursing homes: is site of care associated with visit volume? J Am Geriatr Soc. 2004;52(8):1331-6.

21. Taylor DH, Ostermann J, Van Houtven CH, et al. What length of hospice use maximizes reduction in medical expenditures near death in the US Medicare program? Soc Sci Med. 2007;65(7):1466-78.

22. Teno JM, Gozalo PL, Bynum JP, et al. Change in end-of-life care for Medicare beneficiaries: site of death, place of care, and health care transitions in 2000, 2005, and 2009. JAMA. 2013;309(5):470-7.

23. Center to Advance Palliative Care (CAPC). Improving Palliative Care in Nursing Homes. New York: Center to Advance Palliative Care; 2008.

24. Reynolds KS, Hanson LC, DeVellis RF, et al. Disparities in pain management between cognitively intact and cognitively impaired nursing home residents. J Pain Symptom Manag. 2008;35(4):388-96.

25. Teno JM, Kabumoto G, Wetle T, et al. Daily pain that was excruciating at some time in the previous week: prevalence, characteristics, and outcomes in nursing home residents. J Am Geriatr Soc. 2004;52(5):762-7.

26. Teno JM, Weitzen S, Wetle T, et al. Persistent pain in nursing home residents. JAMA. 2001;285(16):2081.

27. National Hospice and Palliative Care Organization (NHPCO). NHPCO Comments on CMS FY2014 Proposed Wage Index Rule [Comment letter to Marilyn Tavenner, Administrator, Centers for Medicare and Medicaid Services]. In: Schumacher JD, ed. June 28, 2013.

28. Huskamp HA, Kaufmann C, Stevenson DG. The intersection of long-term care and end-of-life care. Med Care Res Rev. 2011.

29. Meier DE, Lim B, Carlson MD. Raising the standard: palliative care in nursing homes. Health Aff (Millwood). 2010;29(1): 136-40. 